\title{
DISCUSSION
}

\section{A new instrument for the measurement of soil moisture suction}

\author{
A. M. RIDLEY and J. B. BURLAND (1993). Géotechnique 43, No. 2, 321-324
}

\section{F. A. M. Marinho and R. J. Chandler, Imperial College of Science, Technology and Medicine}

The tensiometer probe developed by the Authors is an important contribution to the measurement of suction in porous materials, and opens up many possibilities of furthering the understanding of many aspects of the mechanical behaviour of saturated and unsaturated soils. In this discussion we present the techniques required to avoid cavitation in the probe, and experimental results which show that the Authors' tensiometer may be influenced by osmotic phenomena.

Probably the most impressive aspect of the Authors' tensiometer probe is that it is able to measure high suctions in water ( $\gg 1 \mathrm{~atm})$ without cavitation occurring in the system. To avoid cavitation in the measurement system, and thus improve the measurement of negative water pressure, the main requirements are as follows.

(a) The water and all surfaces within the measurement system must be pure and clean (e.g. Henderson \& Speedy, 1980).

(b) The surfaces in contact with the water system must be as smooth as possible to avoid or reduce the number and size of crevices. The smaller the surface area the easier it is to avoid cavitation.

(c) The system should be evacuated by vacuum application in order to remove the maximum amount of air entrapped into the crevices, although it is unlikely that all the air will disappear (e.g. Jones, Overton \& Trevena, 1981).

(d) Pre-pressurization of the system to high pressure is required in order to dissolve all the free air (e.g. Harvey, Barnes, McElroy, Whiteley, Pease \& Cooper, 1944).

If these requirements are followed carefully, it is possible to use an ordinary high pressure transducer to measure soil water suction, and a special design of tensiometer probe with low water volume is not required. We have performed some tests using a Keller (PR-27-100) transducer in conjunction with a 15 bar air entry porous stone, in which suctions of the order of $3.5 \mathrm{MPa}$ were recorded.

Water pressure measurement in soil requires an interface between the measurement system and the soil. Porous stone is such an interface. In the case of negative pressure the porous stone has a particularly important role in controlling the flow of water from the system to the soil.

We used the Authors' tensiometer probe to measure suctions in soil samples prepared with pure pore water and with pore water containing a salt solution $(\mathrm{NaCl}$ at 0.1 molar). With each sample the suction was measured using the Authors' tensiometer; and total and matrix suction were measured separately using the filter paper technique (following Chandler, Crilly \& Montgomery-Smith, 1992). When the filter paper is not in contact with the soil water it measures total suction, the air gap acting as a semipermeable membrane. If the filter paper is in contact with the soil (i.e. it is in contact with the soil water) it measures matrix suction. Subsequent specific referenecs in this discussion to matrix and total suction refer to filter paper measurements.

Figure 5(a) presents the results of suction measurements on statically compacted samples of London clay, prepared, with the addition of pure water, at different water contents. There is good agreement between the tensiometer probe and the matrix suction measurements at suctions of less than $500 \mathrm{kPa}$, but at higher suctions the probe over-records compared with the matrix suctions. Ridley (1993) observed this effect, and suggested that there may have been experimental problems in obtaining good contact between the probe and the soil at high suctions and lower water contents. However, the proportion of pure water added to the compacted clay would have been less at high suctions, so that, assuming a constant salt content in the soil, the salt concentration in the soil will be higher at high suctions. This observation provides an alternative explanation for the observed differences between the matrix suction and the tensiometer probe readings at higher suctions, suggesting that the probe may be measuring total, not matrix, suction.

To check this possibility, total and matrix suctions were measured on a low plasticity clay and on London clay. The samples were again statically compacted, one sample of the low plasticity clay being prepared with pure water and one with the salt solution; a London clay samplc was prepared with the salt solution only. The filter paper 


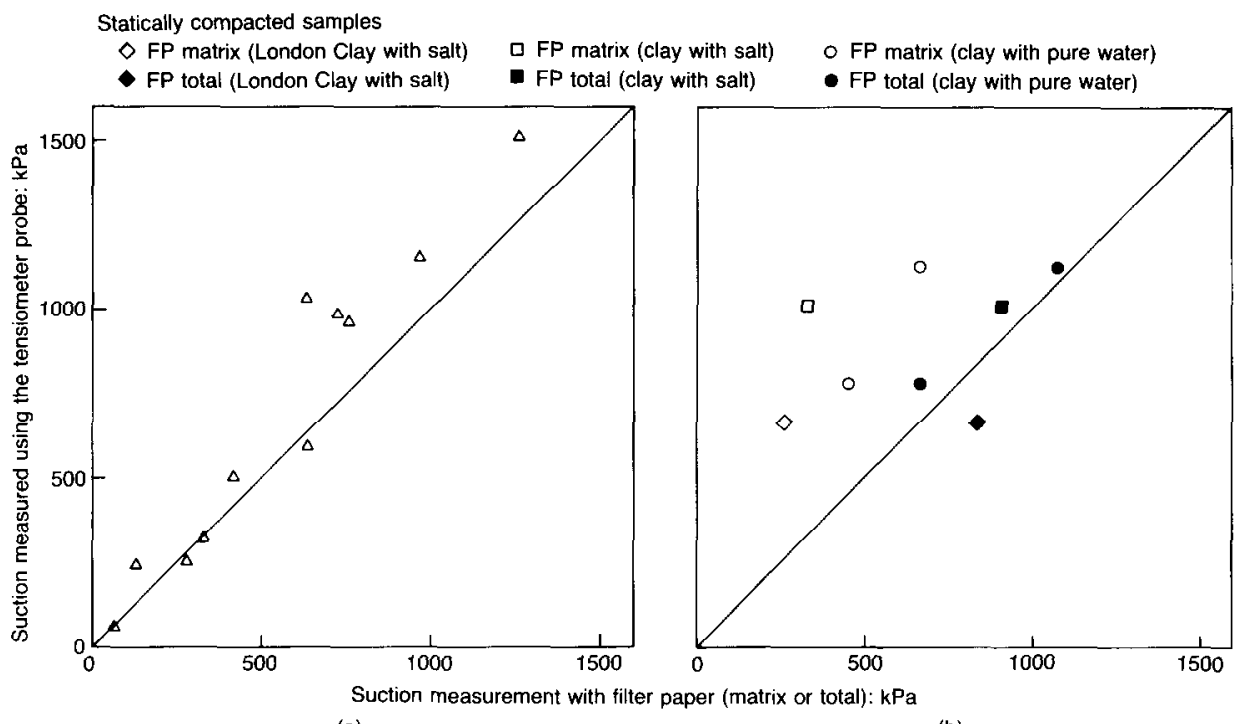

(a)

(b)

Fig. 5. Comparison between filter paper (FP) and tensiometer suction measurement: (a) compacted London clay, samples having added pure water; (b) compacted low plasticity clay and London clay (open symbols indicate matrix suction and solid symbols total suction)

suction measurements are plotted against tensiometer probe measurements in Fig. 5(b). The tensiometer probe readings compare closely with the total suction measurements, and with added salt the difference between matrix and total suction is increased.

These observations suggest that there is an osmotic effect generated by the difference in salt concentration between the tensiometer probe system and the sample, and it appears that the porous stone has some degree of osmotic efficiency. Osmotic efficiency is a measure of the effectiveness of any material in causing hydraulic flow under an osmotic pressure gradient, and also of the ability of the material to act as a semipermeable membrane in preventing the passage of ions while allowing the passage of water (Mitchell, 1991). Osmotic efficiency in the same type of porous stone as used by the Authors was also observed by Schreiner \& Gourley (1993).

Thus it appears that for soils with a salt content the tensiometer probe may measure total suction and not matrix suction.

Figure 5(b) also shows that some samples have a high total suction but a fairly low $(<500 \mathrm{kPa})$ matrix suction. At these suctions the degree of saturation is high, and contact problems with both the probe and filter paper can be expected to be minimal.

It may be concluded that an osmotic suction is developed as an inevitable consequence of the use of a fine porous stone interface in the probe, and that it is the osmotic suction plus the matrix suction that is being measured.

\section{Authors' reply}

$\mathrm{Mr}$ Marinho and Professor Chandler have rasied important issues in relation to the measurement of suction and as a consequence we have carried out further work to help clarify the points they raise.

They list the main requirements to avoid cavitation. We agree with these and believe that the most important requirement is that of prepressurizing the water in the tensiometer to dissolve small amounts of gas which are trapped in the tiny crevices present in the walls of the container and in solid particles in the water.

We were careful to avoid the term 'cavitation' because it is not clear that the limiting suctions obtained using the new tensiometer are controlled by this phenomenon. Further tests have shown that, following a comprehensive saturation procedure, air forms in the measurement reservoir when the measured pressure is about $-1500 \mathrm{kPa}$, i.e. at about the air entry value of the porous stone being used. This is not unexpected, because at this point the pressure difference across the porous stone will be $1500 \mathrm{kPa}$ (assuming standard atmospheric air pressure at the exposed surface). Air will therefore penetrate through the stone and form a bubble in the reservoir. Once this happens the pressure in the reservoir 
becomes about -1 atm. This observation has been confirmed by using porous stones with air entry values of 1,3 and 5 bar that also fail to measure suctions greater than their air entry value. However, air can form in the reservoir at suctions less than the air entry value of the porous stone being used if the tensiometer has not been thoroughly de-aired before use.

On the basis of this argument we are unable to explain $\mathrm{Mr}$ Marinho and Professor Chandler's measurement of a suction of $3.5 \mathrm{MPa}$ using a Keller (PR-27-100) transducer and we have been unable to reproduce the result. However, we do feel that it is possible to measure suctions greater than $1500 \mathrm{kPa}$ using the new tensiometer if a porous membrane (with a high air entry value) is used in conjunction with the porous stone to prevent air entering the system. We have found that the overall performance of the new tensiometer (e.g. the time to achieve de-airing, response time and reliability) is greatly improved when the volume of water is kept as small as possible.

Mr Marinho and Professor Chandler describe experiments on compacted samples prepared with pure water and with salt solutions in which suctions measured with our tensiometer were compared with total and matrix suctions deduced from filter paper measurements. They conclude that the new tensiometer measures total and not matrix suction.

It is important to appreciate that suctions inferred from filter paper measurements depend on a calibration between the water content of the filter paper and suction. Mr Marinho and Professor Chandler have used the same calibration curve (Chandler et al., 1992) to interpret their incontact and out-of-contact filter paper moisture contents. Ridley (1993) proposed that there might be a significant difference between the calibration curve for total suction measurement and the curve for matrix suction measurement because the absorption of water into the paper through the vapour phase (as in total suction measurements) is different from the process of absorption through the liquid phase (as in matrix suction measurement). This results in a maximum filter paper moisture content when absorption is through the vapour phase alone, and hence the calibration curve dips below the calibration curve for matrix suction measurements at suctions of less than about $1000 \mathrm{kPa}$. Research at the Transport Research Laboratory (TRL) (Gourley, Schreiner \& Rolt, 1993) has shown that the calibration curve for total suction measurement is sensitive to

(a) the dimensions of the space in which the out-of-contact filter paper is placed

(b) the exposed surface area of the soil (c) the absolute temperature at which the measurement is made

(d) the time period for which the filter paper is exposed to the soil.

By standardizing the first three criteria calibration curves have been developed which are a function of the time period for the test. The geometry of the system used by us and $\mathrm{Mr}$ Marinho and Professor Chandler is different from the one used by the TRL but we feel that using the calibration curves developed by the TRL to interpret total suction measurements will be more accurate than using the existing matrix suction calibration line. We are grateful to the TRL for granting us permission to use their, as yet, unpublished work.

We have carried out some experiments to assess the significance of osmotic effects when the TRL calibration curves are used for interpreting out-of-contact filter paper measurements. Reconstituted samples were used because the microfabric of compacted soils leads to complications.

Two samples of reconstituted London clay were consolidated one-dimensionally from an initial moisture content of about 1.25 times the liquid limit. One sample was mixed with pure water and the other was mixed with a 0.88 molar sodium chloride solution. This concentration of salt solution should give an osmotic pressure of approximately $4000 \mathrm{kPa}$.

Each sample was consolidated in stages to a final vertical stress of approximately $1000 \mathrm{kPa}$. Care was taken to avoid dilution of the salted sample by filling the oedometer cell with salt solution of identical concentration to that mixed with the sample and by refilling the cell with pure water as the salt solution tended to evaporate. At the end of consolidation the oedometer cells were emptied of liquid to minimize the chance of swelling, and each sample was unloaded quickly to zero vertical stress. Water taken from the oedometer cell of the salted sample had a salt concentration of 1.161 molar, which is equivalent to an osmotic pressure of approximately $5500 \mathrm{kPa}$.

Filter paper not in contact (total suction)

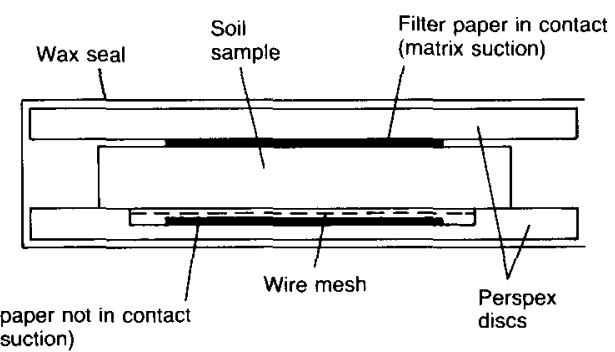

Fig. 6 
The samples were then wrapped in cling film, sealed inside three plastic bags and left for one week to reach equilibrium. After this time suction measurements were made using the new tensiometer. The unsalted sample indicated a suction of $474 \mathrm{kPa}$ and the salted sample indicated a suction of $1278 \mathrm{kPa}$.

Filter paper measurements were then made on each sample, with one filter paper in contact with the bottom of the sample (i.e. measuring matrix suction) and a second filter paper separated from the opposite face of the sample by a wire mesh and an air gap (Fig. 6). After two weeks' exposure to the sample the filter paper moisture contents were as shown in Table 2.

Following the filter paper measurements, a further measurement with the new tensiometer was made on each sample. This indicated a suction of $605 \mathrm{kPa}$ in the unsalted sample and $1182 \mathrm{kPa}$ in the salted sample.

Table 2 shows the deduced matrix and total suctions obtained from the standard calibration curve used by $\mathrm{Mr}$ Marinho and Professor Chandler, and also the total suctions deduced from the TRL calibration curves. These are compared with the measurements made with the new

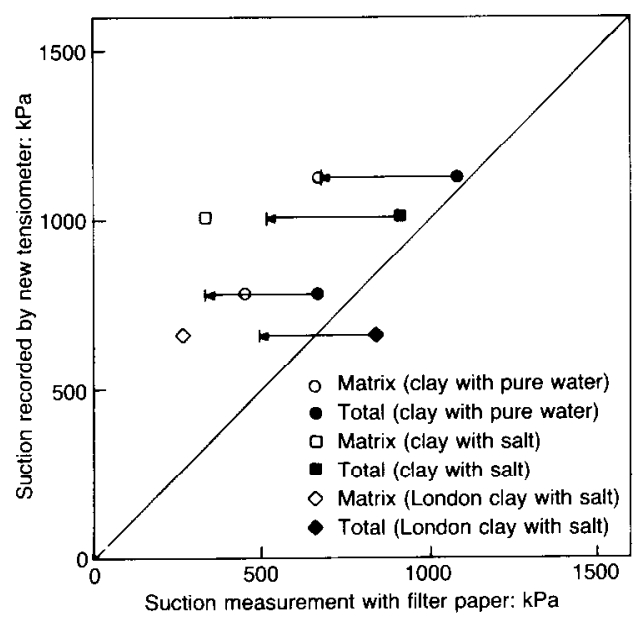

Fig. 7. Statically compacted samples: filter paper measurements (after Chandler et al., 1992) tensiometer. Two important observations can be made.

(a) For both samples the matrix suctions deduced from the filter paper measurements are reasonably close to the suctions recorded with the tensiometer. For the sample prepared using a salt solution the tensiometer gives $15-25 \%$ higher suctions than the values deduced from the filter papers. This is within the range of accuracy that is quoted for the filter paper method, i.e. $\pm 25 \%$ (after Chandler \& Gutierrez, 1986).

(b) In the case of the sample prcpared using a salt solution, the total suction deduced from the TRL curves is in excellent agreement with the expected value of $5500 \mathrm{kPa}$ (knowing the salt concentration) and is much larger than the suctions recorded with the new tensiometer.

It can be concluded from these experiments that the osmotic effects on the tensiometer are small and that it records a suction that is close to the matrix suction as deduced from the filter paper method.

Figure 5(b) shows the suction recorded by the new tensiometer plotted against total and matrix suction deduced using the filter paper matrix suction calibration curve. In Fig. 7 the total

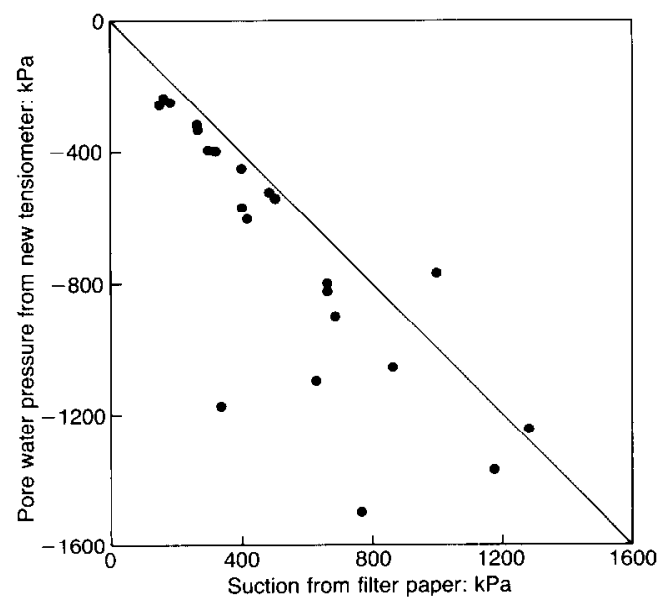

Fig. 8

Table 2

\begin{tabular}{|c|c|c|c|c|c|c|c|}
\hline \multirow[t]{2}{*}{$\begin{array}{l}\text { Pore water } \\
\text { preparation }\end{array}$} & \multicolumn{2}{|c|}{ Filter paper water contents: $\%$} & \multicolumn{2}{|c|}{$\begin{array}{c}\text { Suction } \\
\text { (Chandler et al., } \\
\text { 1992): } \mathrm{kPa}\end{array}$} & \multirow[t]{2}{*}{$\begin{array}{c}\text { Total suction } \\
\text { (Gourley et al., } \\
\text { 1993): kPa }\end{array}$} & \multirow{2}{*}{\multicolumn{2}{|c|}{$\begin{array}{c}\text { Suction using } \\
\text { new } \\
\text { tensiometer: } \\
\mathrm{kPa}\end{array}$}} \\
\hline & In contact & Out of contact & Matrix & Total & & & \\
\hline Pure water & $33-56$ & $28 \cdot 22$ & 568 & 1221 & 800 & 474 & 605 \\
\hline Salt solution & $29 \cdot 45$ & $19 \cdot 5$ & 1024 & 4257 & 5250 & 1278 & 1182 \\
\hline
\end{tabular}




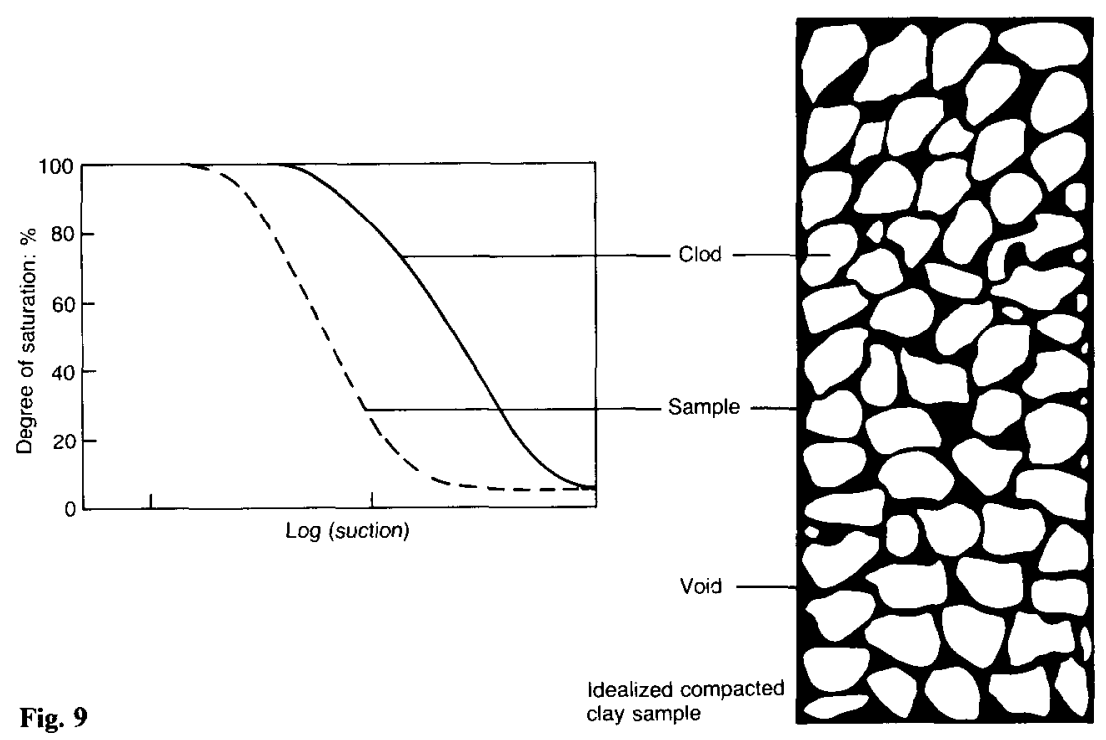

suction results have been reinterpreted using the TRL calibration curves. In every case the deduced total suctions are significantly reduced.

It remains to be explained why the direct suction measurements presented by $\mathrm{Mr}$ Marinho and Professor Chandler on compacted samples are higher than the matrix suctions deduced from the filter paper measurements. Munroe (1993) recorded similar behaviour for compacted kaolin samples (Fig. 8). The deviations between suction measurements made with the new tensiometer and those deduced from the filter paper method are less marked at low suction values. The samples with a lower suction had a higher degree of saturation and a higher density. For suctions greater than $800 \mathrm{kPa}$ the scatter is considerable, although some of the measurements lie close to the equality line.

As the new tensiometer and the matrix suctions deduced from the filter paper agree quite well for reconstituted samples up to suctions in excess of $1000 \mathrm{kPa}$, we believe that the discrepancies for compacted soils may be due to the effects of micro-fabric. Unlike reconstituted soils, compacted soils consist of a series of clods (with a high degree of saturation) in a matrix (Fig. 9) which has many larger air pockets and will usually have a lower overall degree of saturation than the individual clods. Fig. 9 shows idealized curves of degree of saturation against suction for the individual clods and for the whole sample. As the suction increases, the sample begins to desaturate before the clods as air enters the larger voids between the clods.

If the sample is allowed to come to equilibrium over a long time the suctions within the clods and the contacts between the clods will equilibrate. We think that it is this equilibrated suction that the in-contact filter paper measures. However, the new tensiometer makes a measurement quickly and may be affected by the voids between the clods - particularly if the voids are large. If, before placing the tensiometer in contact with the soil surface, evaporation from the voids has taken place, then the tensiometer will tend to overrecord the suction. It seems probable that the recorded suction would decrease to an equilibrium value if measurements were to continue over a longer period and the surface of the sample were protected, to avoid evaporation.

Ridley (1993) measured a variation in the suction (recorded by the new tensiometer) across the surface of compacted London clay samples that had been left open to the atmosphere for a few minutes. On the basis of these measurements and those of Munroe (1993) we recommend that when measurements of suction are made with the new tensiometer on soils with a wide range of void sizes, care should be taken to ensure that the sample is sufficiently protected from the effects of evaporation and that enough time is allowed for the tensiometer to come to equilibrium.

A full experimental investigation is required before definitive conclusions can be drawn regarding the effects of micro-fabric on the measurement of suction. However, it seems clear from both the results of $\mathrm{Mr}$ Marinho and Professor Chandler and our own tests that the discrepancies between the suctions recorded using the new tensiometer and those deduced from the filter paper on compacted soils are not attributable to significant osmotic effects. 


\section{REFERENCES}

Chandler, R. J. \& Gutierrez, C. I. (1986). The filter paper method of suction measurement. Géotechnique 36, No. 2, 265-268.

Chandler, R. J., Crilly, M. S. \& Montgomery-Smith, G. (1992). A low-cost method of assessing clay desiccation for low-rise buildings. Proc. Instn Civ. Engrs Civ. Engng 92, May, 82-89.

Gourley, C. S., Schreiner, H. D. \& Rolt, J. (1993). Filter paper calibration for the TRL suction probe. Project report PR/OSC/002/93. Crowthorne: Transport Research Laboratory. Unpublished.

Harvey, E. N., Barnes, D. K., McElroy, A. H., Whiteley, A. H., Pease, D. C. \& Cooper, K. W. (1944). Bubble formation in animals, 1. Physical factors. J. Cell. Comp. Physiol., 24, No. 1, Aug.

Henderson, S. J. \& Speedy, R. J. (1980). A BerthelotBourdon tubc method for studying water under tension. J. Physics E: Scientific Instrumentation 13, 778-782.

Jones, W. M., Overton, G. D. N. \& Trevena, D. H. (1981). Tensile strength experiments with water using a new type of Berthelot tube. J. Physics D: Applied Physics 14, 1283-1291.

Mitchell, J. K. (1991). Conduction phenomena: from theory to geotechnical practice. Géotechnique 41, No. 3, 229-340.

Munroe, A. S. (1993). The shear strength of unsaturated kaolin with respect to soil suction. MSc dissertation, University of London.

Ridley, A. M. (1993). The measurement of soil moisture suction. PhD thesis, University of London.

Schreiner, H. D. \& Gourley, C. S. (1993). Advanced evaluation of swell tests. Project Report PR/OSC/ 018/93. Crowthorne: Transport Research Laboratory. 